\title{
FROM SKILLSET TO MINDSET: A NEW PARADIGM FOR LEADER DEVELOPMENT
}

\section{Robert Kramer ${ }^{1}$}

$\mathrm{PhD}$, Professorial Lecturer. George Washington University, Washington DC, USA, and Chief Learning Officer, Budapest Academy for Leading Change.

Address: Budapest, Hungary. E-mail: robertkramer@gwu.edu

\begin{abstract}
I argue in this paper that a new paradigm for how leaders should be trained and developed is needed. In the new paradigm, leader development will focus on transforming mindsets more than skillsets. Skills are necessary but not sufficient for leadership. Drawing on the latest discoveries in neuroscience and cognitive science, and the theory of "unlearning" of Otto Rank, I maintain that leaders should be learning how to radically transform their current mental models when they are out-of-date or no longer useful, thereby creating greater capacity for seeing what others cannot see and thinking what others have not yet thought.
\end{abstract}

Keywords: Leadership, leader development, senior civil servants, mindset, adult development.

Citation: Kramer, R. (2016). From skillset to mindset: a new paradigm for leader development. Public Administration Issues, no 5 (Special Issue, electronic edition), pp. 26-45 (in English).

T eaders in business, government and civil society are living in a time of "perLmanent white water" (Vaill, 1989; Vaill, 1996) where the only constant is confusion, unpredictability and shock. In organizations all over the world, wicked social, financial and economic problems fester and go unaddressed for months

\footnotetext{
1 Robert Kramer was International Chair of Public Leadership at the National University of Public Service in Budapest, Hungary, during academic year 2015-2016. In addition to being Professorial Lecturer at George Washington University (Washington, DC, USA), he is now Chief Learning Officer, Budapest Academy for Leading Change (Budapest, Hungary). From 1975-2001, he served as a manager and leader in the U.S. government, including two years on Vice President Al Gore's task force to reinvent the Federal government, the largest organization in the world. His publications have appeared in scholarly journals in the U.S., the U.K. and, in translation, in Austria, Canada, France, Germany, Hungary, the Netherlands and Spain. He is editor of A Psychology of Difference: The American Lectures of Otto Rank (Princeton University Press, 1996) and co-editor with E.J. Lieberman of The Letters of Sigmund Freud and Otto Rank: Inside Psychoanalysis (Johns Hopkins University Press, 2012).

Disclosure Statement

No financial interest or benefit arises from the direct application of this research.
} 
and even years at a time. The volatility of change is swamping the cognitive and emotional capabilities of leaders to respond effectively. What's going on? Geert Bouckaert and Michel de Vries (2013) assert that, in recent years, leading is no longer about addressing clear-cut technical problems with clear-cut technical solutions. Instead, it "is about handling uncertainty, ambiguity, complexity beyond imagination, and significant disagreement about what is going on, why and what should happen" (Bouckaert \& de Vries, p. 8). In my view, these developments demand not just different ways of acting in leadership but also different ways of seeing leadership.

Due to these trends, I believe that a new paradigm for how leaders should be trained and developed is needed. In the new paradigm, leader development will focus on transforming mindsets more than skillsets. I maintain that leaders should be learning how to radically transform their current mental models when they are out-of-date or no longer useful, creating greater capacity for seeing what others cannot see and thinking what others have not yet thought. Such mental maps have many synonyms - "frames", "filters", "belief systems" and "narratives" to name just a few. The quality of the judgement of leaders depends on the quality of their mental models. What, exactly, is a mental model? "Mental models are deeply held internal images of how the world works, images that limit us to familiar ways of thinking and acting. Very often we are not aware of our mental models or the effects they have on our behavior" (Senge, 1990, p. 8).

Therefore, how leaders think and act in moments of uncertainty - the quality of their moment-by-moment mindfulness and capacity for paying attention unfiltered through existing pre-conceptions - is more important than the behavioral competencies they have been traditionally taught in executive classrooms or training workshops. While behavioral skills, especially those involving emotional intelligence (Caruso, Mayer \& Salovey, 2002), remain necessary for leaders to build trusting, mutually respectful, results-oriented relationship with others, they are not sufficient for success at the highest levels of leadership.

\section{The Situation in the U.S., the E.U. and the Russian Federation}

Today in the United States, leaders, according to Van Wart (2013, p. 555), are grappling with mind-boggling challenges such as:

\begin{tabular}{|l|l|}
\hline Leading for results & $\begin{array}{l}\text { - Difficult options to address long-term fiscal stress } \\
- \text { Globalization, high levels of market, business and government failure }\end{array}$ \\
\hline Leading followers & $\begin{array}{l}\text { - Increased cynicism of experienced employees } \\
- \text { Reduced benefits for all employees, including managers and executives }\end{array}$ \\
\hline $\begin{array}{l}\text { Leading } \\
\text { organizations }\end{array}$ & - IT and social media revolutions \\
\hline Leading systems & $\begin{array}{l}\text { - Reinventing organizations to meet citizen and business demands } \\
- \text { Lack of social consensus and cynicism of media and civil society }\end{array}$ \\
\hline Leading with values & $\begin{array}{l}\text { - Lack of trust in business people, in elected politicians and in senior civil servants } \\
\text { learning organization, etc.) }\end{array}$ \\
\hline
\end{tabular}


In the E.U., few leaders have coherent mental maps to make sense of and respond effectively to challenges such as large-scale migration of refugees from the Middle East; global financial instability; record levels of youth unemployment; environmental degradation; and looming terrorism and other law and order threats. Facing the stresses of running faster and faster on a 24/7 treadmill, leaders are finding themselves "in over their heads" (Kegan, 2004): the meaning-making framework of their minds - their mental acuity - is not up to the increasingly complex demands of their responsibilities. The rate of change exceeds the rate of their capacity to master the turbulence. They will need a different form of consciousness - a higher level of mental complexity - to deal with the higher level of complexity of the relentless changes swirling around them. Constantly distracted by the flow of daily crises, many suffer from a kind of leadership "attention deficit disorder": an inability to see a clear path through the blinding fog of "swamp problems". The limits of their ability to pay attention to what is important circumscribes what they can see and, consequently, what they can impact or manage. "Eurocrats have a lot to answer for", complains Nobel-prize winning economist Paul Krugman (2016). "The huge mistake of the euro, the reckless and feckless promotion of austerity, the hapless response to the refugee crisis and in general the failure to take seriously the strains of internal migration." Looking through Krugman's lens, Eurocrats are not paying attention to the right things. They are ignoring the right questions.

Paying attention to the right questions is also lacking in the Russian Federation, where scholars argue, with compelling evidence, that it is necessary to "clean out the Augean Stable of our bureaucracy" (Obolonsky \& Barabashev, 2014). According to Russian scholars, "the chief prerequisite is the political will to transform the system of contracting with civil servants with a view to bringing about change in the Russian bureaucracy and turning it into an honest and professional corporate body that works for citizens" (Ibid., p. 94). Today, few leaders are paying attention to the issue of "political will," the neglect of which negatively affects all relations among business, government and civil society in the Russian Federation.

Why is paying attention so vital? According to Chia (2005, p. 1092), leading "is firstly and fundamentally the task of becoming aware, attending to, sorting out, and prioritizing an inherently messy, fluxing, chaotic world of competing demands that are placed on a [leader's] attention. It is creating order out of chaos. It is an art, not a science. Active perceptual organization and the astute allocation of attention is a central feature of the [leadership] task". After spending 25 years in the U.S. Government, including time on Vice President Al Gore's reinventing government team, I have concluded that "leading" has little to do with the conventional wisdom found in management or public administration (PA) textbooks and "leadership training" programs offered in classrooms by most universities. For example, most tenured faculty in U.S. schools of business or public administration know virtually nothing about research in cognitive psychology and neuroscience, and, therefore, are closed to new ideas widely disseminated in these fields. Typically, senior professors in business and public administration are blind to the new sciences of the brain and mind, and most don't care enough even to learn about them.

Leading, it became obvious to me while I was in public service, is about paying attention to the right problems at the right time and mobilizing stakeholders 
to address them in the right way. The "leading" PA scholars themselves, with rare exceptions (Bouckaert \& de Vries, 2013; Heifetz et al., 2009; Van Wart, 2013a; Van Wart, 2013b), have not been paying attention to leadership even as a general field of study, and, therefore, cannot "lead" (or teach) others, such as senior civil servants, to lead adaptively in their organizations. Typically, PA leadership scholars in the U.S. publish vague, bland generalities such as, "The role of leadership is to obtain resources and deploy those to motivate staff members to perform. It is also a leader's job to ensure that the organization's performance results in accomplishments that serve public needs" (Cohen \& Eimicke, 2002, p. 284). One cannot imagine a less helpful - and more cliché-ridden - definition of the role of leading in public service during a period of worldwide "permanent white water" (Vail, 2006).

If you cannot see a problem clearly, if your attention is focused on the wrong things, you cannot take effective or timely action. You are blind. It's not what senior scholars like Cohen and Eimicke (2002) look at that matters, it's what they see. And they appear to be seeing little or nothing about what is really going on outside the cloistered walls of the U.S. academy, where linear regression analysis and linear structural equation modeling are now seen as the optimal methods of analyzing the complexities involved in leading change in organizations. It is virtually impossible to obtain a tenure-track position in any school of business or public administration in the U.S. without showing that you are an expert in linear structural equation modeling (SEM).

SEM is the "hottest" statistical methodology today in the U.S., just as t-tests, factor analysis, correlation, chi-square tests and analysis of variance (ANOVA) were "hot" about 50 years ago. Today, to get a $\mathrm{PhD}$ in management or public administration, a doctoral candidate must master every aspect of SEM. But isn't conducting research that employs SEM often an unconscious way for us to tell a highly complex, nonlinear story through a highly complex set of linear equations for the purpose of persuading our skeptical peer reviewers that we have found an objective, scientific way to generalize about highly unpredictable human beings? Here is a recent example of the misuse and abuse of SEM by West and Berman (2002), two well-known authors in the U.S. In an award-winning article published in a top-tier journal, these authors constructed a linear structural equation model of "ethics training," "moral leadership by senior managers," and "citizen trust" without understanding that classroom training on ethics is utterly different from practicing ethical behavior in real time, with real people and real ethical challenges. As someone who saw leaders practice their art (it is not a science!) at the highest levels of the U.S. government, I cannot repeat enough times: leadership is not linear; leadership cannot be modeled via linear techniques like regression and SEM; leadership deals with the irrational and the unknown, not the rational and the known. I have concluded that professors with $\mathrm{PhDs}$ who specialize in sophisticated statistical research methodologies know virtually nothing about the day-to-day challenges of leading change in complex times and hard places. When interviewed (Bolman \& Deal, 2008, p. 27), many practicing organizational leaders candidly admit:

- We are not sure we know what the problem is. Definitions are vague or competing, and any given problem is intertwined with other messy problems. 
- We are not sure what is happening. Information is incomplete, ambiguous, and unreliable. People disagree on how to interpret information that is available.

- We are not sure what we want. We all have multiple goals that are unclear or conflicting. Different people want different things. This leads to political and emotional conflict.

- We do not have the resources we need. Shortages of time, attention, or money make difficult situations even more chaotic.

- We are not sure who is supposed to do what. Roles are unclear, there is disagreement about who is responsible for what, and things keep shifting as players come and go.

- We are not sure how to get what we want. Even if we agree on what we want, we are not sure (or we disagree) about how to make it happen.

- We are not sure how to determine if we have succeeded. We are not sure what criteria to use to evaluate success. Or if we do know the criteria, we are not sure how to measure the outcome.

\section{Adaptive Challenges}

Today, all over the world, senior leaders are grappling with enormous challenges far beyond their current mental capacities and also far beyond the current knowledge base of public administration scholars and policy experts in the U.S. There are no pre-packaged or "best practice" solutions to any of the wicked problems these leaders face. Making solutions even harder to reach, the most common cause of failure in leadership, according to Heifetz et al. (2009), is treating adaptive challenges as if they were technical problems. Technical problems can be solved with the application of existing expert knowledge. However difficult they may be, and however much they tax a leader's cognitive abilities, the critical knowledge and competencies already exist to solve the problem. To be sure, technical problems are not trivial. For example, in the field of medicine, replacing a heart valve during open-heart surgery is a technical problem, even though it's an arduous, extraordinarily complex procedure. Why technical? Because it involves mastering techniques that expertly trained surgeons have been able, over many iterations, to test and refine successfully. Solving technical problems, although requiring great skill, involves following established knowledge, proven guidelines and procedures known to experts. These skills are, therefore, trainable.

On the other hand, adaptive challenges are those for which the necessary knowledge to respond does not yet exist, so training in "best practices" inevitably falls short (Heifetz et al., 2009). Both the problems and the solutions are unclear. Adaptive challenges require the creation of new knowledge and new capacities. These are not technical problems with agreed-upon expert solutions. The kinds of wicked challenges leaders face today are "swamp problems" of volatility, uncertainty, complexity and ambiguity. No one knows what to do. Unfortunately, no amount of skillset or competency training - or linear structural equation modeling - to prepare leaders to face these challenges is sufficient. Prior knowledge no longer works. Expert solutions are contradictory, inapplicable or no- 
where to be found. The adaptive leader must facilitate new ways of seeing and new ways of thinking. Reframing or reconceiving what is to be seen and thought, the adaptive leader must learn how to pay closer attention to what others cannot yet see, what others have not yet thought. The knowledge to address an adaptive challenge - for example, the migration crisis in Europe - must be discovered or created on the spot, moment-by-moment, in the acts of people collaborating, under severe time pressure, intense media coverage and budgetary limits, to address it. Technical training programs, no matter how well-designed, cannot deliver adaptive learning results. While training in leadership skills and behavioral competencies remains valuable and necessary, something in addition to skillset development is now necessary.

In this paper I argue that to be effective in the current "swamp conditions", leaders will have to develop new mental capabilities - new ways of seeing in real time, moment-by-moment, in the very process of working on the leadership challenge. To address wicked problems successfully, they must be able to create new knowledge on the spot, not merely apply existing knowledge or past practices. Linear regression techniques are not only useless; they are positively harmful if used to address wicked problems. When no one knows what is going on or what to do, new ways of thinking are necessary, not new statistical methods. This involves changing how leaders know, not changing what they know. The structure of a leader's mind is more important for executive functioning and decision making than the content of a leader's mind. Therefore, I believe that mindset not skillset is now the determining factor in how well leaders perform. (For a similar argument in the field of human resource development, see Kennedy, Carroll \& Francoeur, 2012).

\section{Mindset}

What, exactly, is "mindset"? Although there is no consensus definition in psychology or neuroscience, our "mindset", in common parlance refers to the worldview, mental model, or set of beliefs and assumptions we hold about ourselves, our organizations and the challenges we face. The mental models that compose our mindset "govern", to use an apt metaphor from political science, how we see, think, feel and act. They direct our attention. They are the rules or neuronal programs in our mind that construct our thinking. Non-consciously, almost completely outside our awareness, they frame the world for us. Moreover, we cannot see anything not within our worldview. "At first we are subject to (or immersed within or unable to see) the rules that drive us. They are as invisible as the air we breathe, and just as necessary" (Garvey Berger \& Johnston, 2015, p. 178). Without a doubt, evolutionary processes have determined that human beings "need" these invisible rules or programs in the mind. Mental models have evolved because they make us efficient so that that we do not have to expend valuable energy rethinking every routine situation (Kahnemann, Slovik \& Tversky, 1982). Automatically generated mental models are necessary. We cannot live without them. These are habits of the mind. Habits are especially useful for solving technical problems, which do not require rethinking practices that worked in the past and will continue to work today. Linear regression is an excellent 
tool for solving technical problems. But rethinking automatic patterns of seeing is exactly what is needed in today's world of permanent volatility, uncertainty, complexity and ambiguity. By definition, meeting adaptive challenges requires that leaders examine their own mental models and rethink them - and help others do the same. Otherwise the blind will be leading the blind. And evolution is not kind to the blind.

According to neuroscience, what we perceive and how we make sense of the world - as individuals or as leaders of groups, organizations or societies - is filtered through a cognitive prism that contains what we learned as children; our taken-for-granted beliefs, assumptions and values; formal theories and systems of thought taught to us as adults; our paradigms or mental maps; and the cultural conditioning prevalent in our societies.

Figure

\section{The Prism}

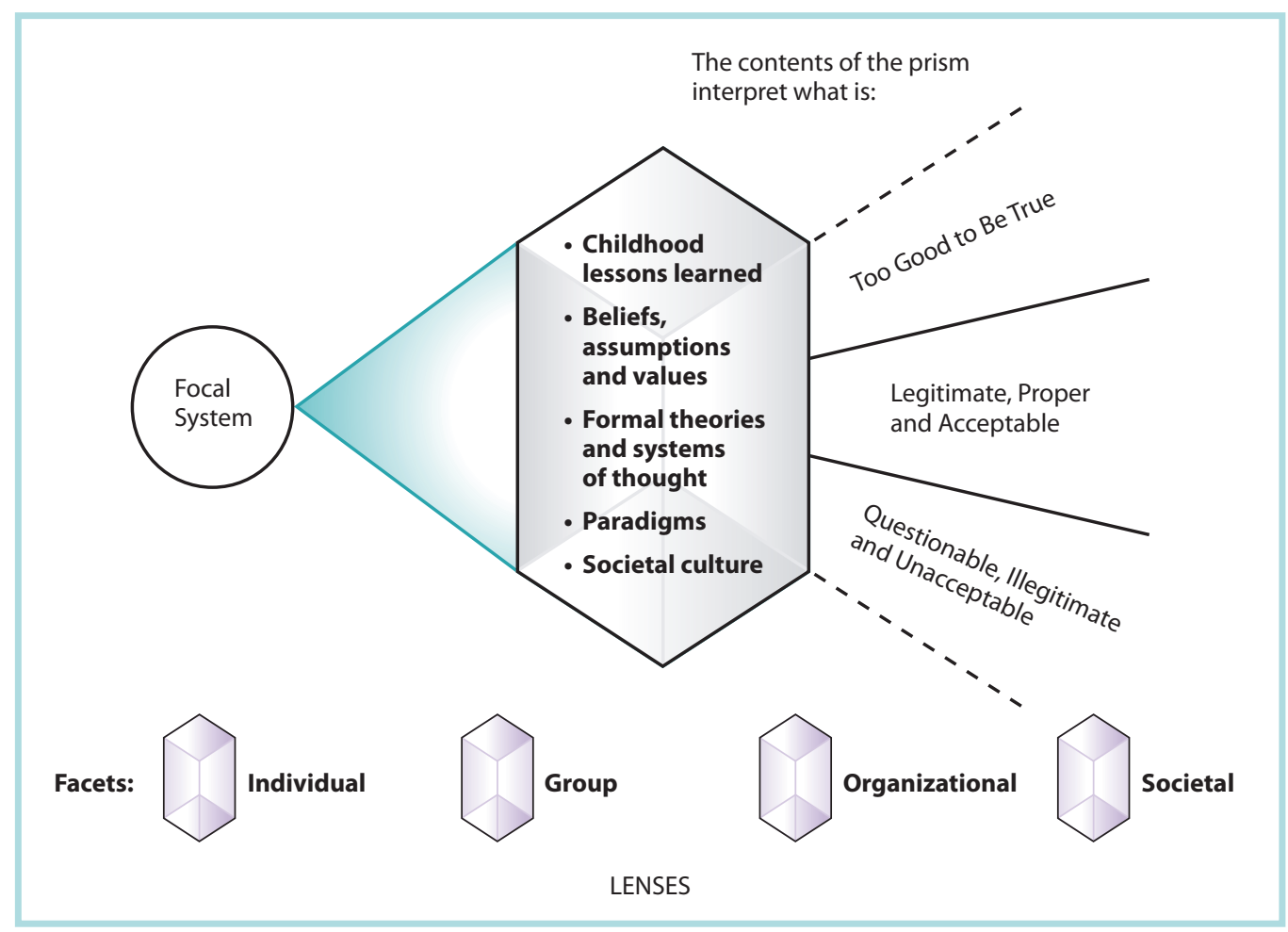

* Copyright approval for publication has been obtained.

Our prism is the mental framework that organizes meaning-making for us. Metaphorically, it's the lens through which we look at ourselves and the world. Our prism contains the "structure" of our mind. Each "focal system" (i.e., individual, group, organizational, or societal) has its own prism through which it interprets what is too good to be true, what is legitimate and proper, and what is questionable, illegitimate and unacceptable: 
The contents of the focal system's prism thus become a primary determinant of how things will be seen and interpreted. Whether the glass is half full or half empty depends on your prism and not on the actual quantity of water in the glass. There are also a number of belief components that exist within the prism, as seen in the accompanying illustration. Each component plays a part in defining how things will be seen and interpreted by the focal system (Marshak, 2006, p. 22-23).

A leadership mindset temporarily suspends prior professional training - including training offered by management or public administration faculty who are usually blind to new ideas from other disciplines - and prior cultural indoctrination. A leadership mindset sees and, therefore, acts freshly.

When taking a higher perspective, the seer can now "see" his or her own prism. This lets leaders change perspective on their own stream of thought. "Instead of being swept away by that stream we can pause and see that these are just thoughts - and choose whether or not to act on them" (Goleman, 2013, p. 203). Along the same lines, the neuroscientist Daniel Siegel (2012) recommends that visioning be cultivated by developing what he calls mindsight, the act of seeing into our own mind, not just observing our external behavior. Siegel defines mindsight as "a kind of focused attention that allows us to be aware of our mental processes rather than being swept away by them" (p. xi).

\section{Changing "How" We Know, Not "What" We Know}

The developmental psychologist Robert Kegan (2000) defines what "develops" in leader development as a radical change in the way leaders know, not a change in what they know. Their form of knowing is transformed as the mind sees more of itself. The ability to see oneself, to look back at and examine the structure of one's prism, is what we mean by "reflection" (re-flec-tion: Latin: stepping back). The act of reflecting means "not just to look, but to look at the act of looking itself; not just to think, but to think about thinking itself; not just to learn, but to learn about learning itself" (Koestenbaum, 1991, p. 62). The act of reflecting, as Socrates first taught over two thousand years ago, means seeing the seer.

According to Kegan (2000, p. 53), discovering increasingly sophisticated ways of knowing - which is another way of talking about seeing differently - is a gradual process by which what was "subject" or invisible in our way of knowing becomes "object" or visible:

That which is "object" we can look at, take responsibility for, reflect upon, exercise control over, integrate with some other way of knowing. That which is "subject" we are run by, identified with, fused with, at the effect of. We cannot be responsible for that to which we are subject. What is "object" in our knowing describes the thoughts and feelings we say we have; what is "subject" describes the thinking and feelings that has us. We "have" object; we "are" subject.

How well leaders pay attention to, observe and interpret the complex social, economic and political systems in their environment will determine their effectiveness. As the paradigm of leader development shifts from skillset to mindset, leaders will begin to learn to become conscious of what they usually take for granted: how they see the world and how they might learn to pay attention to what 
is usually invisible to them. They will be learning "meta-awareness, [paying] attention to attention itself, as in the ability to notice that you are not noticing what you should and correcting your focus" (Goleman, 2013, p. 197). They will begin to learn how to surface and examine their own taken-for-granted assumptions, beliefs and perceptual frameworks - in other words, how they see the world through their prism, and the narratives they construct about what they see. According to Kegan and Lahey $(2009$, p. 222), in the new paradigm of leader development, "we must join a change in behavior with a change in the way we think and feel and in order to change the way we think and feel, we need to change our mindsets" - i.e., change the way we see.

How leaders (and scholars who teach leadership) see or "know" leadership and how they demonstrate effectiveness when in top roles - depends entirely on the lens or prism through which they look at and make sense of the world. A mental framework is a mental map. What leaders perceive when they look through their prisms, and how they interpret and make meaning of what they see, determines what they do. Beliefs drive action. Leaders are meaning makers, actively making sense through their mental frameworks - perceiving, sensing, categorizing - of what's happening around them. Research is showing, however, that some leaders are more capable than others in interpreting and responding, moment by moment, to the complexities of the challenges they face (Kegan, 1994). They can adapt - therefore, the term "adaptive leader" - and are agile under almost any circumstances. What makes such high-performing leaders successful?

Adaptive leaders have learned how to update their mental models on the spot - see with new eyes - and make meaning in fresh, unfiltered ways to respond effectively to challenges (Heifetz et al., 2009). When necessary, they create new mental maps, revise old ones and think anew. They have the courage and wisdom to drop or "unlearn" unproductive ways of thinking and acting. They are not locked into only one way of seeing, one interpretation, one solution, one narrative. They leverage paradoxes and polarities rather than choose one pole at the expense of the other. They are dialectical ("both-and") rather than dichotomous ("either-or") thinkers. Relentlessly curious about everything going on around them, they are unembarrassed to say, "I don't know" - not a stance manifested by leadership scholars in the U.S. concerning their own lack of knowledge about leading in organizations. (How many professors who teach leadership, I often wonder, have led any organization, small or large?)

Unless leaders can admit that they don't know, they cannot begin to learn anything new or see anything different from what they have always seen. In order to learn, they must shift from a condition of unconscious incompetence to conscious incompetence. They must begin to grasp that they don't know that they don't know. "Some years ago, Argyris (1991) noted that one of the biggest challenges faced in the teaching of "experts" or professionals was their tendency to make light of what was being taught them, because they presumed that they already knew what was being taught" (Harrison, Leich \& Chia, 2007, p. 338).

"In the beginner's mind there are many possibilities - said a Zen master - but in the expert's there are few" (Suzuki, 1970, p. 1). Adaptive leaders demonstrate a beginner's mind. They question their own assumptions and beliefs. In order 
to think afresh, they regularly step back from, and reflect on, their own mental frameworks, ideologies, habits of mind, and expectations. They take no belief system for granted as "true" or "valid" without examining it closely. When necessary, they know how to change their own minds and are skilled at helping others do the same. They have a self-transforming mind. In short, leading and learning are the same for adaptive leaders:

Whatever else leaders do, their primary role is to keep learning and to facilitate the learning of those around them... Constant change requires something beyond managing to stay on a predetermined course. It requires leading, i.e., learning whether changing conditions are altering the landscape of needs and opportunities and requiring a change in existing plans or goals; learning which alternative courses might be possible or desirable; learning which direction to go; learning what it takes to get there; learning, learning, learning. In this sense, the crucial question in leadership development is not just what to learn, but how to learn how to learn (Antonacopoulou \& Bento, 2004, p. 82).

\section{Mindfulness and Mindlessness}

Learning how to learn means learning how to see anew, taking nothing for granted. Adaptive leaders consistently show a capacity for what cognitive psychologists and neuroscientists call "mindfulness" (Jain et al., 2007; Shapiro \& Carlson, 2009). To be mindful is to have increased ability, moment-by-moment, to discern new categories and perspectives that improve insight, problem-solving and effective actions. To be mindful is to have the capacity to "discover in the real time of the situation how to act effectively" (Vail 1996, p. 155). Curiosity and openness to self-inquiry are the foundations of mindfulness. Mindful leaders keep their whole mind awake, and continually adjust their perceptions and performance on a moment-by-moment basis to meet the unique requirements of the situation (Csikszentmihalyi, 1996). They have a "reflective conversation with the situation", and listen, with curiosity and close attention, to the "backtalk" coming from the environment (Schön, 1983). Embracing the need for continual learning they have the courage to ask questions of themselves, in the here-and-now, about what others take for granted. Mindful leaders are capable, in real time, of examining and - where appropriate - revising the prisms or mental frameworks they and others have been taught to apply from the past in order to interpret and act in the present. According to recent neuroscientific research (Goleman, 2013, p. 197), "mindfulness boosts the classic attention network in the brain's fronto-parietal system that works together to allocate attention. These circuits are fundamental in the basic movement of attention: disengaging your focus from one thing, moving it to another, and staying with the new object of attention".

When leaders make decisions on the basis of previously established categories, judgments and distinctions, they are liable not to see the full scope of the adaptive challenges they are facing - treating them, instead, as technical problems. The structure of their prism blinds them:

The trouble starts when I fail to notice that I see only what confirms my categories and expectations but nothing else. The trouble deepens even 
further if I kid myself that seeing is believing. That's wrong. It's the other way around. Believing is seeing. You see what you expect to see. You see what you have labels to see. You see what you have the skills to manage. Everything else is a blur (Weick \& Sutcliffe, 2001, p. 47).

When I see only what confirms my categories and expectations, I am not acting mindfully. I am acting mindlessly. According to Ellen Langer, the Harvard social psychologist who pioneered empirical research on mindfulness:

When we are mindless, we are trapped in rigid mindsets, oblivious to context or perspective. When we are mindful we are actively drawing novel distinctions, rather than relying on distinctions drawn in the past. This makes us sensitive to context and perspective. When we are mindless, our behavior is rule and routine governed. Essentially we freeze our understanding and become oblivious to subtle changes that would have led us to act differently, if only we were aware of them. In contrast, when mindful, our behavior may be guided rather than governed by rules and routines, but we are sensitive to the ways the situation changes (Langer, 2008, n.p.).

Mindlessness is "like being on automatic pilot" (Langer, 1997, p. 4), when we rely on past categories, and fixate on a single perspective without seeing that things could be different.

As leaders engage with the complexities of their organizational lives, the prism or cognitive map through which they look at the world needs to transform to meet the increased demands and complexities of the challenges they face. Higher demands need higher mental capacities. Our rate of learning, as the U.K. management scholar Reg Revans famously said, must be equal to or greater than the rate of the change going on around us. To remain effective problem solvers, the minds of leaders must grow "larger" to incorporate more complexity - optimally, an increased capacity for tolerating and dealing with paradoxes, uncertainty, volatility and multiple perspectives. "While we do not often consider the growth of people's minds in the same way we consider the growth of their skills, both kinds of growth have a vital part to play in a person's success and effectiveness" (Garvey Berger, 2012, p. 9).

\section{Mindset and Skillset: Both Are Needed}

Let's pause for a moment. I have been arguing that helping leaders learn how to transform their own mental models ("mindset") is a more powerful method for leader development than using traditional training techniques that focus solely on adding new skills to a leader's behavioral repertoire of competencies ("skillset"). Now I want to add an important qualification. Obviously, development of both skillset and mindset is necessary for leaders. To be sure, we want our leaders to be highly skilled in communicating, negotiating, managing conflict, building trust and many other essential skills and behaviors. These are vital skillsets for leaders and should continue to be emphasized, taught and practiced in all leader development programs. But in my opinion a focus on transforming mindsets is more critical for success at the very highest levels. Research is showing that "technical and administrative/managerial skills alone may be inadequate as leaders face many ill-defined and novel problems" (Day, Harrison \& Halpin, 2009, p. 123). 
The effectiveness of senior leaders can only be assessed by how well they respond in real time under conditions of "permanent white water" (Vail, 2006), when no one knows what to do but immediate action is essential. No single set of skill-based or behavioral competencies - e.g., planning; communicating; listening; meditating; deciding; cross-cultural awareness; managing conflict; etc. is sufficient to make a high-performing leader (Cook-Greuter, 2004, p. 276).

According to the new paradigm, in order to be high performers, leaders must learn how to be fully present in the here-and-now, ready to adapt with agility and resolve to any challenge. They must learn how to reflect on their own mindsets, in real time, and let go of or drop assumptions and beliefs - ways of being - that may have helped them to succeed in the past but are no longer effective. This represents a profound transformation in mental capacity. Such a transformation involves learning to unlearn just as much as it does learning to learn. "As those in the lifespan development field have proposed, successful aging consists of an ongoing tension between gains and losses. The eminent lifespan developmental psychologist Paul Baltes states it bluntly in these terms: "... any process of development entails an inherent dynamic between gains and losses ... no process of development consists only of growth or progression"' (cited in Day, Harrison \& Halpin, 2009, p. 241). We have to learn how to lose or drop values, assumptions, beliefs and expectations that don't address the Now. We have to learn not only how to learn, but how to unlearn.

I have discovered that unlearning is the only way to transform existing prisms and increase the ability to see through new prisms. "Such a process of unlearning comes through a direct confrontation between the current system of sense making and expectation and the shock of an alternative plausible interpretation of reality" (Harrison, Leitch \& Chia 2007, p. 338). But what, exactly, is unlearning?

\section{Learning How to Unlearn}

The first to see that transformation begins with "unlearning" rather than "learning" was the Viennese psychologist Otto Rank (1884-1939), who broke with Freud in the mid-1920s over the failure of Freud to see that training patients who were lying passively on the couch in the language of the theories (e.g., the Oedipus complex; narcissism; etc.) published in the peer-reviewed "scientific" psychoanalytic journals was indoctrination into a "prism" rather than transformation. After leaving Freud, Rank (1929) brilliantly explored new ways to release and unleash the creative life force of his patients not their sexuality, which, he believed, would naturally accompany release of the creative urge. "The creative artistic personality," wrote Rank (1932, p. 28), "is thus the first work of the productive individual, and it remains fundamentally his chief work".

In the "banking model" of training, information is deposited "into" people by breaking into their shells from the outside (Dewey, 1933). Comparing the process of unlearning to the "breaking out" process of birth, Otto Rank was the first psychologist to suggest that a continual capacity to separate from "internal mental objects" - from internalized institutions, beliefs and neuroses; from the restrictions of culture, social conformity and received wisdom - is the sine qua non for 
life-long creativity (Kramer, 1989). Unlearning means separating, breaking away from, dropping, letting go of, tearing the fabric of our conventional thinking, feeling and acting.

Unlearning necessarily involves separation from one's self, as it has been culturally conditioned to conform to familial, group, occupational or organizational allegiances. According to Rank (1932, p. 375), unlearning or breaking out of our shell from the inside is "a separation [that] is so hard, not only because it involves persons and ideas that one reveres, but because the victory is always, at bottom, and in some form, won over a part of one's ego". You have to learn how to separate not only from others but from yourself. You have to learn how to change yourself, by separating from your own ego. This separation may be extraordinarily painful and requires deep listening and compassion from those helping managers to become adaptive leaders (Kramer, 1995a; Kramer, 1995b).

In the organizational context, learning how to unlearn is vital "because what we have learned has become embedded in various routines and may have become part of our personal and group identity" (Schein, 2004, p. 321). We refer to the identity of an individual as a "mindset". We refer to the identity of an organizational group as a "culture". Adaptive leaders learn how to question, probe and separate from, both kinds of identity - i.e., their "individual" selves and their "social" selves. By opening themselves to critical inquiry, they begin to learn how to emancipate themselves - how to unlearn. The slow process of breaking out of one's self-imposed iron cage, of separating from one's internalized objects, constitutes unlearning, which inevitably carries with it fear and emotional pain. By the mid-1920s, Otto Rank had developed a remarkably prescient theory of learning, unlearning and relearning (Kramer, 1996; Lieberman \& Kramer, 2012). Rank's model, the first one ever developed in psychology, is now being confirmed by neuroscientific research.

In the process of developing adaptive leadership capacity, human beings will be physically changing the neural networks in their brain. According to Richard Davidson (2000, 2004), who has used Functional Magnetic Resonance Imaging (fMRI) to discover the neuroscientific correlates of mindfulness, the brain responds to focused attention by altering its neural circuitry. The science of neuroplasticity is the study of the brain's ability to re-organize itself by forming new neural connections throughout life. This is how the brain responds to unexpected challenges (Glimcher, 2003). In psychological terms, becoming a mindful or adaptive leader is the equivalent of developing a "bigger mind". In neurobiological and chemical terms, mindfulness creates new neural connections (learning) and prunes old ones (unlearning).

When we learn something new, neurons fire together and wire together, and a chemical process occurs, called "long-term depression", or LTD (which has nothing to do with a depressed mood state). Unlearning and weakening connections between neurons is just as plastic a process, and just as important, as learning and strengthening them. If we only strengthened connections, our neural networks would get saturated. Evidence suggests that unlearning existing memories is necessary for new memories in our networks (Doidge, 2007, p. 117). 


\section{Transformative Action Learning}

Transformation requires both learning new ways to see and unlearning old ways. Transforming a leader's mindset requires transforming the leader - changing parts of the leader's identity. One such process of identity-based leader development is called "transformative action learning" (Kramer, 2007a; Kramer, 2007b; Kramer, 2008; Kramer \& Kelly, 2010), which I first introduced in the executive education program at American University, in Washington DC, in 2002.

It is beyond the scope of this paper to elaborate on this method, but a few words are in order. The term "transformative action learning" refers to a group of managers working together to address a complex leadership challenge, transforming their mindsets, taking action and getting results. While they explore action steps, they are simultaneously learning from, supporting and coaching each other in a safe, non-judgmental environment. In this setting, they can relax their defenses; they do not have to pretend to know all the answers; it's OK not to know. Through dialogue and mutual inquiry, they learn how to address the seen and unseen aspects of the leadership challenge. Together, they search for the meaning of the unseen by asking each other powerful questions about the prisms or lenses through which they look at the world.

The optimal group size in transformative action learning is 5-7. Meetings usually take place (off-site) at least one day a month, but sometimes weekly or even daily, over the course of a group's life. On a rotating basis, each group member serves as a "problem holder", and shares an adaptive challenge or wicked problem with the others. (Technical problems are not suited to this process; only adaptive challenges.) Privacy is strictly maintained. Nothing confidential leaves the room without permission of the problem holder. All participants must sign a confidentiality agreement. All participants must get written approval, a kind of learning contract, from their boss to participate.

The action learning members will (a) listen to the problem holder's leadership challenge, (b) explore through questions the visible and invisible issues underlying the challenge, (c) offer questions, coaching and tentative directions for action steps, and (d) reflect, together with the problem holder, on the lessons of leading change, peer coaching and mindset transformation learned by everyone during the session.

Transformative action learning facilitates the capacity of leaders to learn how to reflect on and transform their own mindsets - at the same time that they are struggling to understand, change and improve the performance of their organizations, and simultaneously take action. This is not conventional classroom training, which involves lecturing or showing PowerPoint slides. Over the course of weeks, with the compassionate but challenging support of trusted colleagues and a certified action learning coach, members will experience asking deep questions of themselves and each other about what leading in their organizations means to them; what challenges they are struggling with; what they know and don't know; and what they are capable of accomplishing in the organization.

Transformative action learning is the art of making the invisible visible. In the process of unpacking a wicked problem, group members are learning how to increase their mindfulness and effectiveness in a leadership role. They are learning how to learn, unlearn and relearn Kramer and Kelly, 2010). When 
practiced on a regular basis with trusted colleagues, transformative action learning accomplishes four objectives simultaneously:

- It helps group members unpack, tackle and resolve adaptive challenges.

- It helps promote deep listening, strong emotional bonds, peer coaching and team building.

- It helps group members learn how to see their own mindsets and become more mindful and compassionate as leaders toward others.

- It helps plants the seeds of a learning, unlearning and relearning culture in the organization.

The most important purpose of transformative action learning is to help re-structure leaders' prisms in a safe and non-threatening way to deal more effectively with the "mental demands of modern life" (Kegan, 1994). As an outcome, transformative action learning supports leaders in becoming more adaptive and "recognizing that ambiguity and volatility are the fabric of a complex world - eliminating them (if it were even possible) would leave us in a world less rich and wonderful than the one we inhabit" (Garvey Berger \& Johnston, 2015, p. 179).

Transformative action learning allows organizations to tackle and solve "wicked" problems while, at the same time, fostering individual and group-level leadership skills, knowledge and abilities. Why did I call this process transformative? Because it involves transforming the way leaders think. The result is increased individual and group capacity to cope with complexity and sharply different perspectives, and produces the building blocks of a learning organization (Kramer \& Kelly, 2010).

Over an approximately ten-day process, members of transformative action learning teams will:

- Identify the complexities involved in learning to lead their organizations, especially in untangling technical problems from adaptive challenges (based on Ronald Heifetz's model);

- Learn the three phases of adult development (based on Robert Kegan's model) along with different strategies for leading followers or subordinates at each phase;

- Use the four components of emotional intelligence (based on Daniel Goleman's model);

- Apply the process of transformative action learning (based on Robert Kramer's model) in order to surface taken-for-granted values, assumptions, beliefs, and expectations;

- Inquire about and unpack an ill-structured or "wicked" organizational problem;

- Take action steps that will benefit the mission of the organization; and

- Learn, unlearn and relearn from all their actions (based on Otto Rank's model as modified by Robert Kramer).

Usually I begin by working with the highest leaders of an organization to identify a few (1-3) complex organizational challenges along with identifying an "executive sponsor" for each challenge. Then I meet with each executive sponsor (often the highest leader himself or herself) to assess the suitability of the problem for 
the action learning process; clarify my role, the role of the executive sponsor, and the roles of the team members. I provide detailed guidance for the composition of an effective action learning team. Who is needed to get the job done? What roles are essential? Who should not be invited? The executive sponsor for each organizational wicked problem then appoints about 6-7 people to each team.

\begin{tabular}{|c|c|}
\hline Days 1-3: & $\begin{array}{l}\text { The first three days are experientially-based. I focus on experiential exercises to help } \\
\text { team members develop the leadership knowledge, skills and abilities necessary } \\
\text { to use the transformative action learning methodology. I help participants learn such } \\
\text { skills as active listening, asking powerful questions, reflecting, strategic thinking, } \\
\text { and problem solving. I require each team member to select one or more personal } \\
\text { leadership developmental goals on which to work during the transformative } \\
\text { action learning process. I challenge team members to "let go" of taken-for-granted } \\
\text { assumptions of leadership and problem solving - "psychic prisons" built over the } \\
\text { years that limit our mind's ability to see and solve problems. I teach participants } \\
\text { how to observe themselves observing leadership challenges. They learn how to see } \\
\text { the seer. This powerful form of self-awareness focuses on how to unlearn; on how } \\
\text { to discuss topics that are usually undiscussable; on how to ask high-quality questions; } \\
\text { and on how to value not knowing. }\end{array}$ \\
\hline Days 4-5: & $\begin{array}{l}\text { I introduce team members to the structure of the transformative action learning } \\
\text { model. By the end of day five, the teams have engaged in the necessary steps to fully } \\
\text { implement the transformative action learning model and have developed a plan for } \\
\text { implementation over the next } 4-6 \text { months. }\end{array}$ \\
\hline Days 6-10: & $\begin{array}{l}\text { After the initial week, certified action learning coaches attend up to five meetings, } \\
\text { on site, with the teams. As the coaches meet with the teams, they work to gauge } \\
\text { progress on unpacking the problem, review individual leadership development plans, } \\
\text { and assess future steps. I encourage transformative action learning teams to share } \\
\text { what's working well and what's not working well. I also encourage team members } \\
\text { to meet on their own and to consider their transformative action learning project } \\
\text { as a vehicle for bringing to light their capacity as a "learning leader" and a "teaching } \\
\text { leader" (Kramer \& Kelly, 2010). I challenge team members to reflect periodically } \\
\text { on the following vital questions over the course of their transformative action } \\
\text { learning project: } \\
\text { - Are those on my team growing as human beings? } \\
\text { - Are they meeting their developmental goals? } \\
\text { - Are they more willing to ask questions about their own values, assumptions, beliefs, } \\
\text { and expectations? } \\
\text { - Are they increasing their "headroom"? } \\
\text { - Are they more likely to become learning leaders in their own right? } \\
\text { - Are they willing to experience negative capability? } \\
\text { - Is my team taking action steps and learning from them? }\end{array}$ \\
\hline
\end{tabular}

In the new paradigm of leader development, where mindset becomes more of a focus than skillset, some of the key questions for researchers include: How do leaders' meaning systems - their mental frameworks - evolve over time? Are there predictable stages in which advances in adult mental development occur? If the mind has the capacity to become more complex over the lifespan, what level of mental development is optimal for leaders facing adaptive challenges? How might executive education programs promote the capacity of top leaders for higher levels of attention and more mindfulness? In my opinion, researching these questions will provide some of the most exciting possibilities for understanding the future of leader development in the coming years. 
A recent article published by young scholars provides a prescription for how leadership should be studied in the future. Their prescription corresponds closely to my own views: "The state of leadership studies is rather fragmented. While varied methods, contexts and frameworks contribute to a robust body of work, the larger question is how these approaches advance the knowledge base and practice of ... leadership ... we specifically recommend that leadership scholars think bigger... At the same time, we recommend that scholars look closer... Our hope is that this investigation provides both a map of leadership studies over time and also a call for action to intentionally and strategically pave the road ahead" (Chapman, Getha-Taylor, Holmes, Jacobson, Morse \& Sowa, 2015, p. 16).

I admire these young scholars, but I am not optimistic that minds can be changed. For decades, tenured U.S. professors, especially in a marginal field like public administration, comfortable in their ivory towers, have been thinking smaller and not looking closer. Will the newer generation of scholars be able to teach anything to the older generation, most of whom have made it a habit to reject any different perspectives in their field? Sadly, achieving tenure in universities in the U.S. is often an excuse not to learn anything new outside your "discipline" or read anything not published in your field's "top-tier" journals. As John Kenneth Galbraith (1971, p. 5) observed, "Faced with the choice between changing one's mind and proving there is no need to do so, almost everyone gets busy working on the proof".

\section{REFERENCES}

1. Antonacopoulou, E.A. \& Bento, R.F. (2004). Methods of "Learning Leadership": Taught and Experienced. In: Sorey, J. (Ed.). Leadership in Organizations: Current Issues and Key Trends. London: Routledge.

2. Bolman, L. \& Deal, T. (2003). Reframing Organizations: Artistry, Choice and Leadership. San Francisco: Jossey-Bass.

3. Bouckaert, G. \& de Vries, M. (2013). Training for Leadership (Editions juridiques Bruylant).

4. Chapman, C., Getha-Taylor, H., Holmes, M.H., Jacobson, W.S., Morse R.S. \& Sowa, J.E. (2015). How public service leadership is studied: An examination of a quarter century of scholarship. Public Administration, no 94, vol. 1, pp. 1-18. 
5. Chia, R. (2005). The Aim of Management Education: Reflections on Mintzberg's "Managers not MBAs". Organization Studies, no 26, vol. 7, pp. 1090-1092.

6. Cohen, S. \& Eimicke, W. (2002). The Effective Public Manager, Third Edition. San Francisco: Jossey-Bass.

7. Cook-Greuter, S.R. (2004). Making the Case for a Developmental Perspective. Industrial and Commercial Training, no 36, pp. 275-281.

8. Csikszentmihalyi, M. (1996). Creativity: Flow and the Psychology of Discovery and Invention. New York: Harper Perennial.

9. Dewey, J. (1933). How We Think. A Restatement of the Relation of Reflective Thinking to the Educative Process, rev. ed. Boston: D. C. Heath.

10. Davidson, R.J. (2004). Well-Being and Affective Style: Neural Substrates and BioBehavioral Correlates. Philosophical Transactions of the Royal Society (London), no 359, pp. 1395-1411.

11. Davidson, R.J. (2000). Affective Style, Psychopathology, Resilience: Brain Mechanism and Plasticity. American Psychologist, no 55, pp. 1196-1214.

12. Doidge, N. (2007). The Brain that Changes Itself: Stories of Personal Triumph from the Frontiers of Brain Science. New York: Penguin Books.

13. Galbraith, J.K. (1971). Economics, Peace and Laughter. New York: New American Library.

14. Garvey Berger, J. \& Johnston, K. (2015). Simple habits for complex times: Powerful practices for leaders. Stanford, CA: Stanford University Press.

15. Glimcher, P. (2003). Decisions, Uncertainty and the Brain: the Science of Neuroeconomics. Cambridge: MIT Press.

16. Goleman, D. (2013). Focus: The Hidden Driver of Excellence. New York: Harper.

17. Harrison, R.T, Leitch, C.M. \& Chia, R. (2007). Developing Paradigmatic Awareness in University Business Schools: The Challenge for Executive Education. Academy of Management Learning \& Education, no 6, pp. 332-343.

18. Heifetz, R.A., A. Grashow and M. Linsky. 2009. The Practice of Adaptive Leadership: Tools and Tactics for Changing Your Organization and the World. Boston: Harvard Business Press.

19. Jain, S, Shapiro, S.L., Swanick, S., Roesch, S.C., Mills, P.J. \& Bell, L. (2007). A Randomized Controlled Trial of Mindfulness Meditation versus Relaxation Training: Effects on Distress, Positive States of Mind, Rumination and Distraction. Annals of Behavioral Medicine, no 33, pp. 11-21.

20. Kahneman D., Slovik, P. \& Tversky, A. (1982). Judgement under Uncertainty: Heuristics and Biases. Cambridge: Cambridge University Press.

21. Kegan, R. (1994). In Over Our Heads: The Mental Demands of Modern Life. Cambridge: Harvard University Press. 
22. Kennedy, F., Carroll, B. \& Francoeur, J. (2013). Mindset not Skillset: Evaluating in New Paradigms of Leadership Development. Advances in Developing Human Resources, no 15 , vol. 81 , pp. 10-26.

23. Kramer, R. (1989). In the Shadow of Death: Robert Denhardt's Theology of Organizational Life. Administration and Society, November, no 21, pp. 357-379.

24. Kramer, R. (1995a). The Birth of Client-Centered Therapy: Carl Rogers, Otto Rank, and "The Beyond". Journal of Humanistic Psychology, no 35, pp. 54-110.

25. Kramer, R. (1995b). Carl Rogers Meets Otto Rank: The Discovery of Relationship. In Pauchant, Thierry (Ed.). In Search of Meaning: Managing for the Health of Our Organizations, Our Communities, and the Natural World. San Francisco: Jossey-Bass, pp. 197-223.

26. Kramer, R. (Ed.) (1996). A Psychology of Difference: The American Lectures of Otto Rank. Princeton, N.J.: Princeton University Press.

27. Kramer, R. (2007a). How Might Action Learning Be Used to Develop the Emotional Intelligence and Leadership Capacity of Public Administrators? Journal of Public Affairs Education, vol. 13, no 2, pp. 205-246.

28. Kramer, R. (2007b). Leading Change through Action Learning. The Public Manager, winter, vol. 36, no 3, pp. 1-7.

29. Kramer, R. (2008). Learning How to Learn: Action Learning for Leadership Development. In: Morse R. \& Buss, T. (eds.) Innovations in Public Leadership Development. Washington DC: M.E. Sharpe and National Academy of Public Administration, pp. 296-326.

30. Kramer, R. \& Kelly, J. (2010). Transformative Action Learning in the U.S. Government. In: Dilworth, R.L. \& Boshyk, Y. (Eds.) Action Learning and its Applications. New York: Palgrave Macmillan, pp. 43-54.

31. Krugman, P. (2016). Boris Bad Enough. The New York Times, 23 April.

32. Langer, E.J. (1997). The Power of Mindful Learning. Cambridge: Perseus Publishing.

33. Langer, E.J. (2008). Mindfulness and Mindlessness. Available: http://secondjourney. org/newsltr/Archives/LangerE_08Sum.htm (accessed: 5 June, 2015).

34. Lieberman, E.J. \& Kramer, R. (2012). The Letters of Sigmund Freud and Otto Rank: Inside Psychoanalysis. Baltimore: Johns Hopkins University Press.

35. Marshak, R. (2006). Covert Processes at Work: Managing the Five Hidden Dimensions of Organizational Change. San Francisco: Berrett-Kohler Publishers.

36. McCauley, C.D., Drath, W.H., Palus, C.J., O’Connor, P.M.G. \& Baker, B.A. (2006). The Use of Constructive-Developmental Theory to Advance the Understanding of Leadership. Leadership Quarterly, no 17, pp. 634-653.

37. Mezirow, J. and Associates. (2000). Learning as Transformation: Critical perspectives on a Theory in Progress. San Francisco: Jossey-Bass. 
38. Obolonsky, A. \& Barabashev, A. (2014). How to Clean Out the Augean Stable of Our Bureaucracy. Russian Politics and Law, no 52, vol. 2, March-April, pp. 77-94.

39. Rank, O. (1929). Truth and Reality: A Life History of the Human Will. New York: W.W. Norton, 1978.

40. Rank, O. (1932). Art and Artist: Creative Urge and Personality Development. New York: W.W. Norton, 1984.

41. Senge, P. (1990). The Fifth Discipline: The Art and Practice of the Learning Organization. New York: Currency/Doubleday.

42. Shapiro, S.L. \& Carlson, L.E. (2009). The Art and Science of Mindfulness: Integrating Mindfulness into Psychology and the Helping Professions. Washington, D.C.: American Psychological Association.

43. Suzuki, S. (1970). Zen Mind, Beginner's Mind: Informal Talks on Zen Meditation and practice. Shambala: Boston \& London.

44. Vaill, P.B. (1989). Managing as a Performing Art: New Ideas for a World of Chaotic Change. San Francisco: Jossey-Bass.

45. Vaill, P.B. (1996). Learning as a Way of Being: Strategies for Survival in a World of Permanent White Water. San Francisco: Jossey-Bass.

46. Van Wart, M. (2013a). Administrative Leadership Theory: A Reassessment after 10 Years. Public Administration, no 91, pp. 521-543.

47. Van Wart, M. (2013b). Lessons from Leadership Theory and the Contemporary Challenges of Leaders. Public Administration Review, no 73, pp. 553-565.

48. West, J.P. \& Berman E.M. (2004). Ethics Training Efforts in U.S. Cities: Content and Impact. Public Integrity, no 6, pp. 189-206. 